the environment, of resistance or yielding to surrounding influences, may be greater, but in the long run it attains no further object than that accomplished by its simpler neighbour-viz., the propagation of its species, whilst the price it pays for its greater elaboratenes $s$ of living is its inevitable death. Thus stated it would seem that the differences between these groups are of degree rather than of kind. The more complex vitality of the one is associated with a greater complexity and differentiation of structure, a subdivision of labour, that is, special functions being associated for their more perfect performance with more highly specialised structures, though these same structures, in proportion as they are differentiated, lose the power of selfdivision which is possessed in common with the other vital powers by the simplest form of protoplasm. These are but grades, and all intervening degrees are to be found between the highest and lowest beings. Nor is the difference as regards the incidence of death $f$ undamental; whilst the one individual lives wholly in his immediate descendants, the other lives but in part, bis own identity being lost in his death. But however much this mode of stating the case may conduce to a clearer understanding of the problem at issue, there still remains the unsatisfied question, How is it (or in common phrase, what is the cause of ?) the organism, once that it has reached its maturity, in the full plenitude of its powers both for its own existence and for its own perpetuation, gradually comes to fail, grow old, and die? Why should it not, when once fully established, so continue for all time and remain immortal itself as well as perpetuated in its descendants? Wherein is the explanation to be sought? Is it in the continued effect of surrounding circumstances and conditions the adverse influence of which gradually prevails, or is it from some inherent defect in the vital processes which becomes intensified by time and constant repetition ? In whatever direction the source and nature of the disturbing influence are to be looked for, it would assuredly seem to be in that same region where are to be found the conditions which determine the chemical and molecular changes that constitute nutrition and vitality itself ; and inasmuch as cell division, which is the essential of propagation, is but a phase of that aspect of nutrition known as contractility, it would appear that what knowledge we may come to acquire of the intimate nature of life will equally provide us with the ex planation of the conditions of its origin and of its termination, inextricably linked as these phenomena are. Conceiving as we do that the energies of vitality are the sensible expression of continuous iuterchange in a highly complicated material one phase of which is a building up, or assimilation, to be succeeded at some higher degree of complexity and instability by a breaking down and disassimilation, is it in the anabolic stages that the inherent antecedent that finally arrests the metaboli-m, and with it life, is to be found ? or is it that in the catabulic descent materials may be formed which extrt a slowly increasing pernicious influence on the entire process, autogenetic poisons, in fact, that are invariable accompaniments of protoplasmic change? Or, lastly, may it be some failure in the stimulus, the existence of which is involved in our conception of this same protoplasmic activity? Conformably with our fundamental hypothesis of the nature of nutrition it is difficult to see any other direction in which to look for our desired antecedent. Expressed in terms more in accordance with our grosser conceptions of physiology, does death result from some imperfection in the nutritive material (ingesta) or in some toxic product of waste (egesta), or for want of the needful stimulus to the very changes which involve the material and determine the products? That it is the soma that dies and that the life of tbe soma or individual is identical with its nutrition wourd, consistently with our present hypothesis, make it probable that $s$ mewhere within these concepts what we are seeking is to be fourd.

As may be supposed, many suggestions have been offered which find their place in one or other of these categories. Some, with Mr. Herbert Spencer, have sought to explain the phenomena by assuming a failure in the nutritive supply or in the ability to approprlate the ingesta on the part of the organism, the same conditions, in fact, as those which deter mine the limits of size peculiar to each living being However true this may be, it gives no explanation for the inability displayed by the tissues. Among the theories which are based upon the determining cause of death being produced in the course of the changes which constitute life may be mentioned that of Lendl. According to him the protoplasm in the course of its living forms waste products from which the germ plasm at first starting is free; as the cell divides these materials-termed by him "ballast"are restricted to one of the resulting pair, and in the course of the subsequent growth and development. of the organism those morphological units which form the perishable soma are loaded with ballast, whilst those which are destined to the perpetuation of the species, whether they be limited to the sexual elements, as is usually the case, or form a part of the general structure, as seen in some leavese.g., begonia-are free from the noxious material and in consequence escape death. It need scarcely be said that no. proof of this hypothesis exists any more than there does of the suggestion that it is the presence of an aldehyde in. living protoplasms which serves as the stimulus to its activities and that death is caused by a want of this. substance. Others have assumed that the stimulus to vitality emanates from the nucleus which in the process of living becomes gradually exhausted and is finally extinguished.4There is one circumstance which seems to bear a very constant relation to the onset of death-viz, the reproductive. effort. In very many beings this effort is made but once, and then as a rule death soon follows. In others the effort is capable of being repeated over a period (maturity) of varying length, but when it fails senescence sets in. A review of all the circumstances would seem to show that fail. ing vitality follows the cessation of reproduetive capability rather than that this latter fails because of approaching death, and, if we may speculate with others, it appears to beamong the possibilities that the lacking stimulus is to be found in connexion with the sexual elements themselvessome ferment, may be, such as we assume to exist in those lately recognised internal secretions the potensy and influence of which in respect to nutritive processes we are but just gaining a glimpse of. An aralogue for my suggestion is perhaps to be found in the case of the thyroid and thymus glands which exercise a profound control over tissue nutrition and even over growth itself. So may it be with the reproductive organs and their produets. Exhaust d by their efforts to perpetuate the individual, they no longer liberate that stimulus (call it provisionally ferment, internal secretion, or what you will till more precise knowledge defines it) which is needful for the maintenance of the nutritive processes of maturity, and for lack of which the individual deteriorates and dies. May it be that there is a real truth embodied in the experiments of Brown-Séquard, however incomplete they have hitherto been in results?

Based on some such considerations as these I have put forward must be, I take it, the full comprehension of the nature of death as we are in the habit of witnessing it at the bedside. We speak of cardiac failure, of fatal intoxica tion, whether from within or without, of arrested nerve influence and the like, but the real meaning of such phrases, imperfect as they are and often quite inadequate to explain why death should have happened, must be somewhere in the region I have now been groping in. Moreover, the very foundations of prognosis, if not of treatment, so far as this may attempt to modify nutritive processes by drugs or other reagents, must be built upon an understanding of the intimate nature of life and the inherent causes of its failure and cessation.

\section{A NOTE ON SURGEON-LIEUTENANT- COLONEL LAWRIE'S ADDRESS ON THE CAUSE OF MALARIA.}

BY GE O R G E THIN, M.D. ST. AND:

IF, as I believe, the man who stimulates interest in a new subject is a public benefactor, Sargeon-Lieutenant-Colonel Lawrie deserves the title. Amongst the many in whom suck interest is excited there is almost the certainty that some few individuals will be induced to applyz themselves to its study, and there is thus a great likelihood of fresh knowledge being obtained. The celebrated telegrams to the Times intimated to the whole world that Surgeon-Lieutenant Colonel Lawrie was engaged in the study of malaria, and thousands of readers for the first time learnt from these telegrams that the Italian physicians believed that malaria

4 For the discussion of various theories on the intimate nature of death see La Structure du Protoplasme et les Théories sur I’Hérédití par Professor Delage, 1895 
was caused by a parasite, and by reading them many medical men doubtless learnt for the first time that there might legitimately be two sides to this question. If I judge by my own experience, Surgeon-Lieutenant-Colonel Lawrie's lecture at Bombay, reported in the Times of India, the Indian Laneet, the British Medical Journal, and in THE LANCET of May 16th, has fully sustained this interest. As an evidence of this, I may remark that I have received three copies of the Times of India from different sources and one of the Indian Lancet, and some urgent requests for information as to what it all means. I am not sure that even this would have induced me to solicit the courtesy of the pages of THE LANCET were it not that, although my name is not mentioned in Surgeon-Lieutenant Colonel Lawrie's lecture, some pungent remarks are made in it which have direct reference to a publication for which I am responsible; and I do not consider that I should be doing either myself or Surgeon-Lieutenant-Colonel Lawrie justice if I were to pass over his criticisms without remark. The reading of a paper on the Parasite of Malaria by Dr. Marshall of Rio Tinto and myself at a meeting of the Royal Medical and Chirurgical Society was used by the Council as an introduction to a discussion on the whole subject, and I undertook the duty of prefacing the reading of the paper by a short exposition of the views at present held regarding the relation of the parasite to the various forms of malarial fever. To render my remarks more intelligible I úsed diagrams, copied from the works of the authors whose views I endeavoured to explain, and in order that the readers of THE LANCET and British Medical Journal might more easily grasp the meaning of the brief reports of my introductory speech, reduced engravings of the diagrams were printed at the head of the report. Surgeon-Lieutenant-Colonel Lawrie remarks of these engravings that Laveran's bodies (the term by which he designates what we call the parasite) "are not such cells as are depicted in the pictures of THE LANCET and British Medical Journal of Feb. 15th, 1896. These are not correct representations of Laveran's bodies. Some of them appear to be drawn from the imagination, others, especially the rosette form, are caricatures of vacuoles and crenating or disintegrating blood-cells." Now, will the readers of THE LANCET imagine for a moment what this criticism implies? It signifies either that the person employed to make the drawings for the diagrams misrepresented the bodies he was employed to copy or that Marchiafava and Bignami are not familiar with vacuoles and crenating or disintegrating blood-cells. As a diagram is only intended to represent the leading features of a drawing, mine may not have been exact copies in every detail of the original drawings, but the references to Marchiafava and Bignami's works will show that they are correct in every important particular. If this is conceded, Surgeon-Lieutenant-Colonel Lawrie's statement can only be justified by assuming that Marchiafava, a Professor of Pathology of long and great experience, who has been studying blood for considerably more than a decade, and Bignami, the chief assistant in the Pathological Laboratory of the University of Rome, who has also been engaged for several years in the study of blood, does not know a vacuole in a red blood-cell when he sees it, and cannot recognise a crenating or disintegrating blood-cell. The mere expression of the supposition shows its absurdity. Such mistakes are possible by imperfectly instructed beginnners. Nay, I have even seen them made in illustrations of a paper on malaria (not published in Europe), but errors of this kind could not be put on record in Italy where learned societies know something of the value of the observations for whose publication they are responsible. What I have said ought to be enough to show what weight should be attached to Surgeon-Lieutenant-Colonel Lawrie's criticism, but if it is likely to serve any useful purpose I may be pardoned for observing that all the appearances in the challenged pictures, except the appearances of a sporulating crescent from Grassi and Feletti's work, have been verified by myself, and if any student of the subject who is interested will procure a copy of Dr. Marshall's and my paper be will find it illustrated by a plate which shows not only these phases but many intermediate ones. The drawings answer in the affirmative Surgeon-Lieutenant-Colonel Lawrie's question as to whether the successive stages of the development of $\epsilon$ ach species of parasite shown in the reduced diagrams belong to the same body in different phases of its existence. This paper has just been published in the Transactions of the Royal Medical and Chirurgical Society, the papers in which are now to be had separately at a nominal price, and in this one, which $I$ believe costs a shilling, will be found a coloured plate showing the different developmental stages of four varieties of the parasites of malaria. The successive phases were drawn from nature, their continuous development in a selected patient being in each case chosen for illustration. For Dr. Marshall and myself I absolutely disclaim the imputation of not being able to distinguish vacuoles and crenating or disintegrating blood-cells.

Human nature being what it is, it is impossible for any investigation to engage the attention of various observers with out a certain amount of the personal element making itself manifest. Nor is this altogether to be regretted. Rivalry within certain limits whets the desire and capacity to work, and science is the gainer; but these limits are very easily passed, and I am not sure that we are not passing them now in this malaria discussion. I would bardly refer to this element in Surgeon-Lieutenant-Colonel Lawrie's paper if it did not recall a remark that is printed in the report of the discussion in London. As a corresponding impression appears to have been made simultaneously in Bombay, I may explain now that in omitting the names of English and American authors it was not from any disposition on the part of Dr. Marshall and myself to overlook the claims of Anglo-Saxon workers as compared with an undue tendency to overestimate the claims to consideration of the Italian physicians and naturalists whose views we had been quoting. SurgeonLieutenant-Colonel Lawrie's remark about the "devoted worshipper of parasites and foreigners," although it is not addressed to us, was probably suggested by our frequent reference to Italian names. I think these expressions are suggested by a mistaken idea. Already the modern literature of malaria has become so extensive that only the authors of bibliographies can be expected to enumerate all the men who have been industriously working at the subject. Those workers who may prove successful in adding a solid contribution to our knowledge will get the credit of their work irrespectively of authors and of nationalities. In quoting an author in my introductory speech, what was in my mind was not his nationality but what he had done. Now what are the great things that have been done in connexion with the malarial parasite? When speaking of the discovery of its existence is it possible to avoid mentioning Laveran? When speaking of the discovery of the quartan and tertian parasite as separate species is it possible to be silent over the name of Golgi? When mentioning the virulence of the irregular and pernicious fevers of Southern Italy and many other parts of the world is it possible to pass over the name of Marchiafava, who has shown that the parasite which causes them exists as a distinct variety? When discussing the crescent body, that enigmatical form, how is it possible not to explain the views of Grassi and Feletti? Not even excepting Laveran, whose position is unique, these men may from an insular point of view be spoken of as foreigners, and there are people to whom their names may not seem homely; but whatever their names and whatever their nationality both their names and their nationality are linked indissolubly with the discoveries which they have made. True they are mostly Italians, but we ought to be pleased to acknowledge that after Laveran's discovery all the important work has been done in Italy. How much of our knowledge of malaria would still be wanting in precision if it were not for the experiments by which it was shown that if the blood of a man which contains one species of the parasite is injected into the veins of a healthy man that man will develop malarial fever of the type from which the first man suffers, and that in his blood there will develop the same species of parasite that is contained in the blood used for inoculation. By these experiments the existence of separate species of the parasite of malaria was definitely established, and all these experiments were done in Italy. What is there of the first importance that so far has been done in the other countries of Europe and in America? All that we have done is to verify the work of the Italians and endeavour to find methorls by which the clinical observer may more readily discover the existence of the parasite and to speculate as to the directions in which future work may throw light upon the yet unsolred problems. The great question as to how the parasite of malaria gets admission into the human body is yet unsolved and offers an attractive field for investigation to workers in four con. tinents.

The countrymen of John Hunter, Jenner, and Lister can well afford to applaud ungrudgingly the great and laborious work of the Italian physicians, and I hope we shall hear no 
more of comparisons which have nothing better to justify them than the sound of a name or a nationality.

What is the proof of a certain appearance being that of a parasite? Amongst other evidences the chief point is that an organism or organic structure grows and multiplies and reproduces its kind. This can be absolutely proven in regard to what we call the malarial parasite, and what SurgeonLieutenant-Colonel Lawrie thinks is a degenerative bloodcell. The proof of this is already abundantly given in the Italian writings, and an excellent résumé with original illustrations will be found in Mannaberg's book. A similar proof will be found in the drawings illustrating the paper by Dr. Marshall and myself, and additional evidence will be found in the plate which will shortly be published illustrating $\mathbf{m y}$ paper on the parasite of the pernicious fever of Sierra Leone in the same volume. The whole cycle of the organism, from the nucleated spore, not developing within the red corpuscle to begin with, but coming in contact with it, then entering it, becoming larger, and developing in it separate nucleated spores, is illustrated in these two papers, in complete confirmation of previous descriptions, if confirmation is necessary. Surgeon-Lieutenant-Colonel Lawrie only found some of the stages in the patient whom he showed at Bombay, and the sporulating stage was not seen; but this does not justify the remark that "no evidence has been adduced to support the theory that Laveran's bodies sporulate, or, if they do, that the act of sporulation is periodic." I need not again refer to the Italian writers who have all described and drawn the sporulating parasite, but content myself with stating that I demonstrated under the microscope, at the meeting of the Royal Medical and Chirurgical Society, all the phases of the parasite, from the spore stage to the sporulating stage, and Dr. Pringle, by the use of his beautiful photographs, showed us these stages on the screen with the lantern. I shall be pleased to demonstrate these or similar preparations to anyone who has the praiseworthy curiosity to wish to satisfy himself by actual examination of microscopical preparations. The intra- and extra-corpuscular cells described by SurgeonLieutenant-Colonel Lawrie as being found in his patients' blood are, with the crescents, all that is usually to be found in blood taken from the finger of patients affected with the forms of malaria produced by the parasite of irregular fevers discovered by Marchiafava, and of themselves I admit their nature might be well open to discussion. If SurgeonLieutenant-Colonel Lawrie has not seen more than he describes in this case or shows in his diagrams I can quite understand his scepticism. But if blood is taken from the spleen in these cases the sporulating stage will be found, and it is another merit of the Italian physicians to have shown this. To satisfy oneself that the malarial parasite is indeed a parasite, having an independent cycle of existence, it is necessary to examine blood from the finger in quartan or tertian ague, or blood from the spleen in the fevers caused by hæmamoba præcox, the parasite of the summer-autumn fevers of Rome. In some cases these can hardly be found even in the spleen, and I have verified by post-mortem examination that the brain may contain numbers of parasites and the spleen and peripheral circulation be almost entirely free from them. The localisation in irregular fevers of the pernicious parasite in special organs and its rarity, or even absence, in the peripheral circulation is a reason why examinations of blood taken from the finger in fevers in India and elsewhere so often show no parasites. I have satisfied myself that it is often very difficult in Indian fevers to find a parasite in the blood from the finger, although the pigment-laden white corpuscles often show clearly the nature of the case, and are a proof that the parasite is propagating itself in the blood in some internal organ.

The first studies of the malarial parasite should be made on quartan and tertian fevers, in which all the phases can be found in the finger blood. In the irregular fevers common in India the knowledge that can be acquired from the blood from the finger is often very incomplete.

Fortunately for my present purpose it is unnecessary to follow Surgeon-Lieutenant-Colonel Lawrie in his statements regarding the formation of the formed elements of the blood. The fact that he observes a swarming movement in the white corpuscles of the frog similar to the swarming movement of pigment granules of the malarial parasite proves nothing either for or against his views. It shows the liability of very minute inert bodies to oscillate in a fluid medium. There are two kinds of movement of the minute pigment granules to be observed in the parasite. There is the active oscillation waich is due to physical causes, and which is similar to a movement of minute granules often seen in leucocytes, quite different from any protoplasmic movement associated with life. There is another kind of movement of pigment in the living malarial parasite in which the granules follow each other in fixed directions, evidently indicating streams in the protoplasm, and of a totally different character from the oscillatory movement with which we are all familar, and which, I may safely say, has never been observed by Surgeon-Lieutenant-Colonel Lawrie in the white corpuscles of the frog.

Histologists are all familiar with the clear spaces seen in the fine meshwork of the protoplasm of a white corpuscle when it is examined by a high power, which SurgeonLieutenant-Colonel Lawrie appears to consider to be cellular in their nature. They are found in the protoplasma of amœbæ, and that they are not young cells can be shown by the fact that they contain no nuclear elements. In stained preparations it would be impossible to confound them with a sporulating parasite, in which, when the staining is properly done, each spore is seen to contain a well-marked nuclear body. (For the technique best adapted for this demonstration I refer to my paper in THE LANCET of July 6th, 1895.)

I am far from wishing to prejudice the value of SurgeonLieutenant-Colonel Lawrie's investigations into the development of the blood, but it cannot be estimated correctly until he gives us a more detailed description of the objects he describes than is to be found in his address, and until they are fully illustrated by coloured representations drawn to scale. As this is a field of study in which much remains to be done it is to be hoped that Surgeon-Lieutenant-Colonel Lawrie will continue the studies that he has begun with so much zeal and energy, and eventually present the results which he obtains in a form in which they can be appreciated by physiologists. His views on this subject, however, whether they are right or wrong, have no real bearing on the question of the existence of the parasite of malaria. The most characteristic form in which we see this parasite-the sporulating body-has apparently not been seen by him, and of course we cannot expect him to trace for us its development from a white corpuscle. Even the forms which he has seen he has not traced in any form of development from a white corpuscle, and only infers their genetic relation from the trifling and unimportant fact that both bodies contain minute granules in active movement. The repeated demonstrations of the development by multiplication inside the red blood cells of the young amoebæ to the formation of from eight to twenty spores, according to the species of parasite, is only got over by an unhappy attempt to throw doubt on the power to observe and to describe of a great number of highly-trained histologists and pathologists. The existence of the parasite of malaria rests on the same kind of evidence and on as good evidence as the belief that cancer is caused by an abnormal epithelial growth. The latter doctrine must have been accepted at one time by thousands of medical men, who, although they never saw a section of cancerous tissue, wisely gave their confidence to observers whom they knew to be competent. Surgeon-Lieutenant-Colonel Lawrie in his address has given no reason why a similar amount of confidence should not be given to the competency and honesty of the scores of highly-trained men in Europe and America who have described the complete development or cycle of the parasite of malaria.

It is with pleasure that I refer to Surgeon-LieutenantColonel Lawrie's valuable experimental work when he injected malarial blood into dogs and monkeys. He found that this did not lead to a multiplication of Laveran's bodies, which is valuable confirmation of previous work done in the same direction.

Before closing these remarks I should like to be permitted to say something regarding what may be expected from India in relation to these studies. I do not see that we had any reason to expect much more to have been done than has been done already. Doubtless there are many medical men in India and much malaria, but there are many medical men in Fingland and much phthisis, yet how few of them have contributed anything important to our knowledge of tuberculosis and the tubercle bacillus. I have worked at both these subjects, and it may be of some use if I say that the parasite of malaria is a much more difficult subject of study than the tubercle bacillus. I do not think anyone will add much to our knowledge of the parasite of malaria who is not a trained pathologist and has had long experience in the study of blood, whose routine duties do not leave him time for original work, as well as the opportunity of examining 
patients, and who is not skilled in the use of very high powers of the microscope. These form a combination of qualities which will never be found largely represented in the members of the medical profession in any country. I believe the best thing that could be done in the present circumstances would be to send a selection of the young men chosen for the Indian Medical Service for six months to Rome or Catania, where they would not only get plenty of cases for continuous study, but would have the assistance of teachers trained in general pathology as well as specially expert as regards the parasite of malaria. Better still, perhaps, would be three months at Catania and three months at Rome, the best season at each being chosen. These men when sent to India could be specially attached to the medical schools of the large cities, charged with the duty of investigating the whole subject of malaria and of teaching the technique required by practitioners for diagnostic purposes. If a measure of this kind were carried through there is every reason to believe that India would in time contribute its quota to the furthering our knowledge of the disease in which, of all others, it has the greatest interest.

Queen Anne-street, W.

\section{THE VACCINATION LAWS.}

BF JOHN C. McVAIL, M.D., D.P.H.,

MEDICAL OFFICER OF HEALTH OF THE COUNTIES OF STIRLING AND DUMBARTON.

JENNER performed his first vaccination on May 14th, 1796. The centenary of this event has been the subject of national celebration at St. Petersburg. In Berlin, the capital of a country in which vaccination and revaccination are practically universal and small-pox practically nonexistent, Virchow and Koch and Von Bergmann and other men of world-wide reputation have held a great gathering in honour of a " benefactor of the universe." In Jenner's own country the circumstances are different. A Royal Com. mission on Vaccination has been in existence for nearly seven years and has not yet reported, the delay, it may safely be assumed, being due to the determination of the Commissioners to do their work thoroughly when they are at it. Compulsory vaccination in England has, however, in the meantime become a matter of local option, and in an increasing number of places the option, as expressed in the election of boards of guardians, is taking the form of noncompulsion. The growing neglect of vaccination in England is roughly indicated by the returns published annually by the Medical Department of the Local Government Board. The percentage of cases "not accounted for" - that is, infants who have neither been vaccinated nor died - was in 18728.8 in London and 4.5 in the rest of England. For London low-water mark was reached in 1881, when only 5.7 per cent. were not accounted for. For the rest of England the lowest year was 1875, when the percentage not accounted for was only 3. By 1888 the London and "rest of England" percentages had reached 10.3 and 8.2 per cent. respectively, and by 1891 (the latest year for which the data are available) the default had mounted to 16.4 and 12.9 per cent. respectively. No doubt for more recent years the results are still less satisfactory. These high figures are due mainly to neglect of vaccination in particular localities. In many places there is practically no omission to vaccinate, and such percentages as $0.0,0 \cdot 1$, and 0.4 are not unknown. But in Gloucester the "not accounted for" were in 1891 no less than 84 per cent. of the total, in Keighley 83, in Leicester and Northampton 80, in Oldham 78, in Luton 77, in Kettering 75, and so on. In the metropolitan districts the worst figures are for Mile-end old Town, 50 per cent.; for Hackney, 40 ; Bethnal Green, 38 ; Poplar, Greenwich, and Stepney, 19; and Paddington, Camberwell, and Westminster, 17. It is not my present purpose to discuss the value of vaccination and revaccination. $I$ believe that vaccination is of essential importance as a preventive of small-pox, and that perhaps no greater physical boon than the Jennerian prophylactic has ever been conferred on humanity. It is from this standpoint that the question of the vaccination laws is here viewed.

These laws are at present utterly unsatisfactory. Though called compulsory they do not compel. At the most they offer a choice between submission to vaccination on the one hand and payment of a money penalty on the other. The enforcement of this choice is in the hands of boards of guardians. whose practice is anything but uniform. While ore board insists on prosecutions and fines repeated regarding the same unvaccinated child so long and so often as a fixed age limit permits, an adjoining board may be satisfied with a single prosecution, and yet another may absolutely decline to take any action, while every election of guardians may suddenly reverse whatever custom has previously prevailed in the district. Elections ad hoo with all their recognised disadvantages are not infrequent. It thus results that the option to refuse vaccination without prosecution or penalty is not that of the individual, but that of the electoral division in which he resides, while if there is to be any option at all it obviously ought to be personal and not collective. Nor in districts where penalties are inflicted is the choice given between submission and penalty naturally a fair one, as the maximum fine, while bearing heavily on the agricultural labourer, is a trifle in the case of the well-to-do. Cheap martyrdom has temptations for many minds, and the vaccination laws present the opportunity for the desired notoriety. The fine imposed, however trifling, is not paid, imprisonment follows, and the subsequent release is celebrated by music from the local brass band, a demonstration, stump speeches, and a presentation. Carried away by the influence of what Carlyle, speaking Teutonically, calls " swarmery," such scenes result in the wholesale manufacture of anti-vaccination sentiment.

Another defect in the present law is that it says nothing whatever as to the thoroughness of the vaccinal operation. No fact in medical science is better attested than that the amount of protection depends largely on the sufficiency of the protective procedure. Every small-pox hospital bears witness to this, and the evidence applies to every period of life. In illustration it may be recalled that Dr. Gayton, who treated over 10,000 cases of small-pox in the metropolitan hospitals, found that in patients under fifteen years of age 706 who had "good marks" of vaccination had only 7 deaths among them, or less than 1 per cent.; while 2192 who had "bad marks," or though alleged to be vaccinated showed no marks at all, had 209 deaths among them, or over 9 per cent. Among 1504 cases admittedly unvaccinated at the same ages the deaths were 639 , or 42 per cent. The amended law should provide that whoever is vaccinated should be sufficiently vaccinated. No mere sham vaccination ought to be any longer possible to swell the ranks of those who, though registered as protected, are ready to succumb to the first approach of small-pox infection.

In addition to being both irritating and inefficient the law is utterly illogical. In 1853, when the first compulsory Act was passed, the need for revaccination was not sufficiently known. The recognition of its necessity has, indeed. largely grown from the experience of the protective results of infantile vaccination following on the operation of the law of that year. Primary vaccination had previously been performed at any age, but in 1853 the systematic protection of infants was begun, and we now have learned that that protection cannot be relied on to last in full amount throughont the whole of life. And here it may be desirable to note shortly what are the teachings of experience regarding the amount and duration of vaccinal protection. Loss of protection due to a first vaccination varies with varying circumstances. If the operation be performed in infancy then its infuence appears to be gradually weakened or diluted by the growth and development of the tissues and increase in bulk of the body. If it be performed later in life, when development is approaching completion or is already complete, its influence is much more lasting. If, therefore, reraccination be desirable, say, at ten years of age, it does not follow that a third and fourth vaccination should be done at twenty and thirty years of age, and so on. In Germany since 1874 vaccination has been compulsory both on males and females in infancy and again at eleven or twelve years of age. On healthy males a third vaccination is performed when they enter the army, but no evidence has yet been produced of excessive prevalence of small-pox among the female population of Germany through their want of a third vaccination. All the same, circumstances may arise--such as exposure to the infection of epidemic smallpot in a given population-rendering a third vaccination a wise precaution in adult life. if the second raccination has been done a very lono time previously. But the mention of ten to twelve years of age as the proper time for a second 